\title{
O ENSINO DE LÍNGUA PORTUGUESA COM ÊNFASE NOSGÊNEROS DISCURSIVOS, LEITURA E PRODUÇÃO TEXTUAL
}

\author{
BLUMENAU/SC AGOSTO/2018
}

\author{
Jeice Campregher - Uniasselvi - jeice.campregher@uniasselvi.com.br \\ Fabrício Brandão - Uniasselvi - sdfabriciobrandao@hotmail.com \\ Tipo: Investigação Científica (IC) \\ Natureza: Relatório Final de Pesquisa \\ Categoria: Conteúdos e Habilidades \\ Setor Educacional: EDUCAÇÃO INFANTIL E FUNDAMENTAL, EDUCAÇÃO MÉDIA E \\ TECNOLÓGICA
}

\begin{abstract}
RESUMO
Este artigo tem o objetivo de apresentar uma reflexão sobre o ensino de Língua Portuguesa (LP) na escola, com enfoque no viés sociointeracionista dos gêneros do discurso. Para tal, serão contemplados assuntos tais como: Concepção bakhtiniana de linguagem; Letramento e sua relação direta com a língua escrita, seu lugar, suas funções e seus usos na sociedade; O ensino de leitura, produção textual e análise linguística. De igual forma, será exposta uma experiência de observação e de regência em classe, a qual se mostrou enriquecedora quanto aos conhecimentos teóricos e empíricos obtidos na observação e na prática da docência. Essa investigação é fruto do Estágio Supervisionado e do Projeto de Ensino (TCC) realizado no curso de Letras, na modalidade EaD, do Centro Universitário Leonardo da Vinci (UNIASSELVI). Para alcançar o objetivo, foram utilizadas as técnicas da observação, do questionário, do diário de campo e a pesquisa bibliográfica. A partir da investigação, pôde-se compreender que os alunos aprendem de uma forma significativa, uma vez que compreendem os usos da língua/linguagem/do texto. A importância destes aspectos está intimamente ligada ao sucesso que 0 ensino da língua deve alcançar na formação do indivíduo capaz de inserir-se e desenvolver, de forma competente, os diversos usos que a língua possibilita. A experiência foi significativa para o acadêmico em formação, para a docente de turma e para os alunos.
\end{abstract}

Palavras-chave: Ensino. Língua Portuguesa. Prática. Formação.

\section{AGRADECIMENTOS}

AO CENTRO UNIVERSITÁRIO LEONARDO DA VINCI (UNIASSELVI), PELOS EXCELENTES PROFISSIONAIS DA INSTITUIÇÃO. AO CENTRO DE EDUCAÇÃO DE JOVENS E ADULTOS - POR OFERTAR O ESPAÇO PARA A REALIZAÇÃO DO ESTÁGIO. 


\section{INTRODUÇÃo}

Este trabalho é oriundo de duas disciplinas: Estágio e Projeto de Ensino (TCC). Ambas no curso de Letras, modalidade EAD, do Centro Universitário Leonardo da Vinci (Uniasselvi). Durante o Estágio, realizou-se um estudo bibliográfico e uma descrição da experiência vivida. A disciplina de Projeto de Ensino contribuiu com o processo reflexivo e analítico, ampliando o olhar e a compreensão do que foi observado e realizado na escola - em específico, no Centro de Jovens e Adultos de Blumenau, SC.

Este artigo contempla em seu bojo, como área de concentração, o ensino de língua portuguesa e metodologias de ensino da língua portuguesa. A escolha deste tema se justifica diante de sua relevância apontada pela própria teoria - abordada adiante. Essa também sinaliza a complexidade na formação das mais variadas competências e habilidades comunicativas do indivíduo - sendo esse objetivo parte integrante das aulas de Língua Portuguesa. Diante da grande abrangência que o tema possui, será dado enfoque ao aumento dos conhecimentos acerca do ensino da língua, utilizando os gêneros do discurso como ferramentas eficazes para tal empreendimento.

Este trabalho realiza uma reflexão sobre o processo de ensino-aprendizagem de língua materna na escola, sob o viés sociointeracionista dos gêneros do discurso. Para tal, será tomada como base a concepção bakhtiniana de linguagem, bem como do conceito abrangente dos gêneros do discurso. Será proposta uma reflexão acerca do conceito de letramento e seus reflexos na expressão da linguagem escrita. A fim de corroborar a compreensão desses assuntos, lançaremos mão da tríade "ensino de leitura, produção textual e análise linguística nas aulas de língua portuguesa", temas basilares na formação do professor de Língua Portuguesa (LP). Posteriormente será relatada a experiência do período de observações e de regência de cinco aulas. Em seguida, será concluído o trabalho, expondo as compreensões que obtivemos ao longo desse processo, à luz da teoria.

\section{FUNDAMENTAÇÃO TEÓRICA}

O campo de concentração "o ensino de língua portuguesa", atualmente, é bastante discutido. Os estudos do letramento apontam que o ensino deve levar em conta as necessidades que os alunos possuem. Dentre eles, o de adequar os usos da língua nas mais diversas situações e esferas sociais; tanto na modalidade oral quanto na escrita. Para isso, o ensino e a aprendizagem ganham muito ao ser sustentado por um arcabouço teórico que depreenda os processos que envolvam a articulação da linguagem. Dessa forma, a disciplina eleva sua potencialidade, de forma a desempenhar 
com efetividade seu papel de formação de subjetividades engajadas socialmente.

Nesse sentido, ao observar o conceito de gêneros do discurso sob o viés sociointeracionista, percebe-se ele influencia de forma positiva o ensino de língua portuguesa, uma vez que permite compreender com mais eficiência e clareza a relação existente entre linguagem, competência leitora e escrita. Antunes (2007) faz uma análise de como as novas concepções de língua refletem no ensino escolar. Ela destaca que as línguas dão suporte a atividade interativa entre os sujeitos, seja na escrita ou na oralidade, sendo veiculado em diversos suportes e com propósitos comunicativos distintos.

A autora propõe mudanças no ambiente escolar, justamente para que essas novas concepções possam ser introduzidas. Mendonça (2006) apoia essa mudança, evidenciando que, para tal, é necessária a busca por uma metodologia que contemple tanto o código quanto o uso social. Destaca ainda que "a mudança na prática pedagógica que prevemos é gradual e repleta de dúvidas, com passos adiante e atrás, e este parece ser o caminho mais provável e seguro, por paradoxal que pareça" (MENDONÇA, 2006, p. 225). Para Antunes (2007, p.153), "as questões de linguagem fariam parte do interesse e do cuidado de todos os professores da escola". Para a mesma autora, (ANTUNES, 2007, p.154) "a distribuição das aulas havia de contemplar a articulação de vários componentes da língua".

\subsection{OS GÊNEROS DO DISCURSO}

Os gêneros são, conforme Bakhtin (2006, p. 262) enunciados relativamente estáveis. Eles organizam a comunicação verbal. Isso quer dizer que, quando nos expressamos, para materializar em enunciado o nosso querer dizer, fazemos naturalmente uso desses gêneros. Estes estão presentes em nossa cultura, circulam e se constituem nas diferentes esferas da atividade humana. Um exemplo, neste momento, pode ser válido: um professor, ao preparar algum conteúdo para trabalhar com seus alunos, irá organizar um gênero intitulado aula. A aula é um gênero presente na nossa cultura. Ele tem determinada organização, remete a um determinado conteúdo temático, relaciona interlocutores que desempenham papéis bem específicos (o de professor e o de aluno), com fins também específicos. Em outras épocas e em outras culturas, as aulas possivelmente eram/são ministradas de outras maneiras, com outras formas de organização, com outras ferramentas. Isso, porque o gênero sofre modificações ao longo do tempo, de acordo com o contexto e em relação aos envolvidos.

Para Bakhtin (2006), os sujeitos se comunicam, falam e escrevem por meio de gêneros 
do discurso. Os indivíduos, quanto mais se relacionam e fluem em sociedade, mais passam a entender e produzir um repertório de gêneros - em muitos casos, os sujeitos sequer sabem disso. Inclusive nas conversas informais, o discurso é acomodado pelo gênero que se encontra em uso. De acordo com Bakhtin (2006, p.282), os gêneros nos são dados "quase da mesma forma com que nos é dada a língua materna, a qual dominamos livremente até começarmos o estudo da gramática". Esses gêneros possuem particularidades que foram sendo construídas ao longo do tempo e que dizem respeito a aspectos temáticos, composicionais e estilísticos.

\subsection{LETRAMENTO}

O surgimento do conceito de letramento se deu no meio universitário. Embora o termo possa ser classificado como moderno e recente no campo da educação brasileira, de acordo com Soares (2009), esse termo foi utilizado pela primeira vez no Brasil em 1986 por Mary Kato, no livro "No mundo da escrita: uma perspectiva psicolinguística". O conceito de letramento, no princípio, teve uma função específica: "separar os estudos sobre o impacto social da escrita dos estudos sobre a alfabetização, cujas conotações escolares destacam as competências individuais no uso e na prática da escrita" (KLEIMAN, 1995, p. 15).

O letramento, segundo Soares (2009), está investido das práticas de leitura e escrita. Em outras palavras, a aprendizagem dos mecanismos envolvidos no ato de ler e escrever acontece no instante em que o indivíduo se insere no mundo da escrita. Além disso, o indivíduo começa a perceber a necessidade de adequação da linguagem aos contextos e interlocutores - essa percepção também envolve o letramento. A esse respeito Mortatti (2004) afirma:

Letramento está diretamente relacionado com a língua escrita e seu lugar, suas funções e seus usos nas sociedades letradas, ou, mais especificamente, grafocêntricas, isto é, sociedades organizadas em torno de um sistema de escrita e em que esta, sobretudo por meio do texto escrito e impresso, assume importância central na vida das pessoas e em suas relações com os outros e com o mundo em que vivem. (MORTATTI, 2004, p. 98).

Atualmente, muito se fala sobre o ensino e aprendizagem de leitura e produção textual nas aulas de Língua Portuguesa. Apesar disso, ainda existem muitas compreensões e práticas arraigadas em âmbito escolar. Essas reproduzem um modelo de ensino que não atende às reais necessidades dos alunos. Esses necessitam transitar pela sociedade interagindo em situações comunicativas distintas. 
Para Geraldi (1992), temos que respeitar e, ao mesmo tempo, considerar a gramática natural que cada aluno traz consigo, pois é exercendo a linguagem que o aluno vai deduzir a teoria de suas leis. "Por isso, importa ensinar a língua e não a gramática, pois esta deve constituir um dos meios para alcançar o objetivo que se tem em mira" (GERALDI, 1992, p. 121). Antunes (2003, p. 41) corrobora essa tese dizendo que "ela possibilita uma consideração mais ampla da linguagem e, consequentemente, um trabalho pedagógico mais produtivo e relevante".

Diante disso, a partir desses e outros fundamentos teóricos, pretende-se, nos dias atuais, construir um ensino de língua que confira ao aluno uma educação linguística escolar dirigida para a heterogeneidade - de linguagens, de experiências, de gêneros do discurso, de experiências com a/por meio da linguagem. Para atingir tal objetivo, é necessária a busca por uma metodologia que contemple tanto ao código quanto ao uso social.

\section{MATERIAIS E MÉTODOS}

Durante o Estágio Supervisionado, realizado no curso de Letras modalidade EAD, foram observadas aulas na Educação Básica. O campo de estágio foi uma escola de Educação de Jovens e Adultos de Blumenau, Santa Catarina. Os dados técnicos e teóricos relacionados neste artigo são frutos de uma extensa pesquisa bibliográfica acerca do tema proposto. Para este artigo, fez-se um recorte: (1) dos fundamentos teóricos, (2) do que foi observado e realizado em sala e, ainda, (3) das considerações/compreensões possibilitadas pela experiência.

As técnicas utilizadas durante o Estágio foram a observação e o diário de campo. Após coletados os dados a partir do diário, realizou-se uma reflexão a partir dos aportes teóricos - esses resumidamente apresentados na seção anterior. Em especial, os conceitos de gêneros do discurso, letramento, práticas de leitura e escrita levando em conta as necessidades reais dos estudantes em sociedade. Tal reflexão foi potencializada a partir da disciplina Projeto de Ensino - uma das disciplinas da grade de Letras EAD -, que tem o objetivo de realizar um trabalho reflexivo (TCC) apoiado nos estudos das disciplinas do curso, em especial, o Estágio.

\section{RESULTADOS E DISCUSSÃO}

O período de observação ocorreu entre os dias vinte dois de março e cinco de maio de 2017. Foram observadas duas turmas: uma corresponde às séries finais do Ensino Fundamental e, outra, de Ensino Médio. Por trata-se de uma escola "não convencional" 
- Ensino de Jovens e Adultos - a experiência vivenciada em seu núcleo contribuiu muito com a formação acadêmica. Tanto no Ensino Fundamental quanto médio, foi possível observar turmas heterogêneas - jovens, adultos e idosos dividindo o mesmo espaço. Esse contexto possibilita que todos cresçam com as experiências e as percepções uns dos outros.

Ainda sobre a turma, foi possível perceber alunos que, que na grande maioria, não concluíram seus estudos no ensino regular por diversos motivos. Entre eles: tinham que trabalhar para ajudar a família; outros repetiram de anos diversas vezes, perdendo o gosto pelos estudos; outros ainda, por terem algum tipo de déficit de aprendizado, não conseguiam acompanhar suas turmas tradicionais. Isso já demonstra e torna clara a responsabilidade do professor que trabalhe com Educação de Jovens e Adultos (EJA). Com esses alunos, a fundamentação teórica, apresentada neste trabalho, faz ainda mais sentido, uma vez que possuem experiências e circulam nos mais variados contextos de interação humana (práticas sociais, práticas de letramento).

Nas aulas observadas, percebemos o interesse e o comprometimento da professora regente em aplicar o conteúdo de acordo com a proposta pedagógica da escola. $O$ Projeto Político Pedagógico (PPP) está constituído com base nas Diretrizes Curriculares e Parâmetros Curriculares Nacionais. Esse aspecto reflete e é amplamente percebido nas práticas vivenciadas durante este período de observação, momento em que a docente procurou desenvolver em suas aulas as práticas da oralidade, da escrita e da leitura. Foi possível perceber a tentativa de contribuir com o aprimoramento linguístico oral e escrito - dos alunos. Essa postura e as metodologias adotadas vão ao encontro do que atualmente vem sendo defendido quanto ao ensino de língua portuguesa.

O domínio da língua tem estreita relação com a possibilidade de plena participação social, pois é por meio dela que o homem se comunica, tem acesso à informação, expressa e defende pontos de vista, partilha ou constrói visões de mundo, produz conhecimento. Assim, um projeto educativo comprometido com a democratização social e cultural atribui à escola a função e a responsabilidade de garantir a todos os seus alunos o acesso aos saberes linguísticos necessários para o exercício da cidadania, direito inalienável de todos (PCN - Língua Portuguesa, 2001, p.23).

Durante o período em sala, foi possível perceber a dedicação da professora em oferecer aos alunos uma proposta diferenciada. Esta facilitando a aprendizagem - por se apresentar de forma atrativa; tanto pela abordagem quanto por amarrar cada texto e conteúdo à vida social. A cada novo conteúdo ou gênero discursivo trabalhado, por possível verificar que em nenhum momento a professora deixou de fazer amarrações 
com a realidade. Em especial, situações de comunicação concretas que ocorrem diariamente. Nesses momentos, os alunos eram convocados a refletir sobre os usos e funções dos gêneros estudados; além da necessidade de adequação a cada uma das situações de comunicação e diferentes interlocutores.

Por meio dessa postura, foi possível verificar que alunos de todas as idades mostraramse interessados em relação ao assunto abordado. Verificou-se que, quando o aluno compreende que aquilo tem total relação com a vida prática diária, eles se dedicam totalmente àquilo que está sendo trabalhado. Dessa forma, percebeu-se que os aportes teóricos, de fato, fazem sentido em sala de aula e que contribuem com uma prática pedagógica que faça sentido para os estudantes.

Além disso, também foi visível o interesse, por parte da professora, por desenvolver a criticidade e reflexão sobre a língua por meio de aulas dialogadas e dinâmicas, estimulando a participação e a reflexão dos alunos. Tal prática docente priorizou aspectos linguísticos úteis ao desenvolvimento linguístico dos alunos. As atividades permitiram contemplar o desenvolvimento da oralidade por meio de processos de escuta e produção textual, assim como o processo de análise linguística.

Mendonça (2006) entende que a análise linguística representa uma visão crítica e que sugere mudanças quanto ao processo de ensino que envolve a gramática normativa e a produção de textos. Também entende que, adotando um ponto de vista interacionista, o ensino de língua portuguesa deverá levar em conta aspectos comunicativos interacionais da linguagem.

Dialogando com essa visão, os PCNs (1997) também orientam que as atividades pedagógicas do ensino da leitura e da escrita devam considerar o tripé: uso, reflexão, uso. Neste sentido, Geraldi (1984) acrescenta que a pratica metodológica deve assumir uma posição política que reflita uma compreensão da realidade.

Vale ainda ressaltar que a professora observada mantinha uma excelente relação com seus alunos, permeadas sempre pela cordialidade e educação de ambas as partes. Gómes (2000) confirma que é muito importante conceber a relação entre professor/aluno de acordo com o clima estabelecido pelo professor, da relação empática com seus alunos, de sua capacidade de ouvir, refletir, discutir, além da criação de pontes entre o conhecimento docente e os saberes dos alunos.

Após a realização da observação, passou-se à regência. Foram cinco aulas aplicadas em uma das turmas observadas. A metodologia e a abordagem colocaram-se na esteira 
do que já vinha sendo trabalhado com a turma. $O$ trabalho deu enfoque a um gênero em específico: a notícia. A seleção foi em acordo com a professora da turma, tendo em vista que, até o momento, não havia sido abordado.

Iniciou-se com uma reflexão sobre os gêneros, sobre a esfera jornalística e, a seguir, sobre o gênero: a composição, o estilo e a função social do gênero. Analisamos alguns materiais, os componentes e, adiante, houve uma produção a partir de imagens. O resultado foi bastante satisfatório, demonstrando que eles compreenderam os elementos que caracterizam o gênero. Da mesma forma, utilizaram a linguagem adequada conforme foi estudado. Os alunos dedicaram-se a cada uma das etapas realizadas durante essas cinco aulas. Em síntese, essa experiência de sala foi bastante significativa, uma vez que foi possível observar a teoria sendo posta em prática, verificando a aceitação dos alunos e o quanto que eles, ao compreenderem as funções do texto, passam a se dedicar ao entendimento e à produção.

\section{CONSIDERAÇÕES FINAIS}

A experiência da sala de aula - observação e regência - contribuiu sobremaneira para a observação de conceitos da área de Letras na prática. Além disso, essa vivência demonstrou a recepção dos alunos em relação às práticas pedagógicas que se apoiem em concepções de letramento/gêneros do discurso. Da mesma maneira, a aplicação das cinco aulas trouxe contribuições para a formação do acadêmico de Letras. A experiência do estágio contribuiu muito para a troca de experiências - teórica e prática - entre professor de sala e estagiário. Além de termos recebido relatos orais bastante significativos por parte dos alunos daquela turma.

A observação e regência docente acrescentam sobremaneira à formação do educador, uma vez que implica num estreito contato com o ambiente escolar e com a prática pedagógica. Em se tratando de um curso na modalidade EAD, percebeu-se um ganho ainda maior, uma vez que permite o contato com a realidade escolar. Nessa oportunidade, surgem as dúvidas, as inseguranças, a necessidade de seleção metodológica, a necessidade de adaptação linguística à turma, o desafio de tirar as dúvidas dos estudantes, de pensar nos exercícios e dos materiais a serem explorados.

Além disso, a experiência de sala leva o acadêmico a uma experiência de cunho científico: coleta de materiais, análise, reflexão, fundamentação da discussão realizada. Além disso, a observação contribui com o uso do diário de campo, saber ouvir, saber relatar com respeito e ética, perceber a reação dos alunos; além de elaborar um artigo ao final do estágio, desenvolvendo a escrita acadêmica. Tal trabalho, adiante, sendo 
revisitado; construindo outras reflexões em um trabalho final na disciplina de Projeto de Ensino. Esta é uma nova oportunidade de reflexão; é mais um momento de lançar um olhar sensível sobre o que foi vivido e estudado.

Compreende-se, por fim, que a observação não deve limitar-se apenas ao período de estágio, uma vez que seu contínuo exercício se faz necessário durante toda a carreira do professor. Isto é, sempre que, ao deparar-se com situações em que o aprendizado dos alunos se mostre deficiente ou falho, é imprescindível que sua prática seja revista e reformulada com vistas a proporcionar ao aluno uma aprendizagem favorável ao seu desenvolvimento.

\section{REFERÊNCIAS}

ANTUNES, Irandé. Aula de português: encontro e interação. São Paulo: Parábola Editorial, 2003.

BAKHTIN, Mikhail. Muito além da gramática: por um ensino de línguas sem pedras no caminho. São Paulo: Parábola, 2007.

Os gêneros do discurso. In: BAKHTIN, M. M. Estética da criação verbal. São Paulo: Martins Fontes, 2006.

BRASIL. Secretaria de Educação Fundamental. Parâmetros Curriculares Nacionais: Língua Portuguesa. Brasília, 1997.

Ministério da Educação. Parâmetros Curriculares Nacionais: Língua Portuguesa. Brasília: MEC/SEF, 2001. 
GERALDI, João Wanderley (org.). O texto na sala de aula. 2.ed. Cascavel: ASSOESTE, 1984. . João Wanderley. Portos de Passagem. São Paulo: Martins Fontes, 1992.

GÓMEZ, A. I. P. A aprendizagem escolar: da didática operatória à reconstrução da cultura na sala de aula. In: SACRISTÁN, J. G.; PÉREZ GÓMEZ, A. I. Compreender e transformar o ensino. 4.ed. Porto Alegre: Artmed, 2000.

KLEIMAN, A. Os significados do letramento. Campinas: Mercado das Letras, 1995.

MENDONÇA, Márcia. Análise linguística no ensino médio: um novo olhar, um outro objeto. In: BUNZEN, Clécio.; MENDONÇA, Márcia (org.). Português no ensino médio e formação do professor. São Paulo: Parábola Editorial, 2006. p.199-226.

MORTATTI, Maria do Rosário Longo. Educação e Letramento. São Paulo: UNESP, 2004.

SOARES, Magda. Letramento: um tema em três gêneros. $3^{\text {a }}$ ed. Belo Horizonte: Autêntica, 2009. 